\title{
Unfavorable Mandibular Body Fracture Associated with First Molar Removal: Report of a New Case
}

\section{Faryabi J and Mehrabizadeh $\mathrm{H}^{*}$}

Department of Oral and Maxillofacial Surgery, Kerman

Medical University, Iran

*Corresponding author: Mehrabizadeh $\mathrm{H}$, Department of Oral and Maxillofacial Surgery, Kerman Medical University, Shafast Dentistry School, Iran

Received: May 03, 2017; Accepted: May 23, 2017;

Published: J une 12, 2017

\section{Abstract}

First molar extraction is one of the most common procedures performed in dentistry units. It is sometimes accompanied by complications such as alveolar osteitis, infection, hemorrhage, dysesthesia and also iatrogenic fracture. This article describes a rare case of mandibular body fracture that occurred in patient during the extraction of one erupted first molar, including a brief review of the literature.

Keywords: First molar extraction; Complication; Mandibular fracture

\section{Case Presentation}

A 28-year-old female was referred to our department by a general dental practitioner (GDP) after the dentist attempted to extract the patient's lower first molar tooth with forceps. She was a healthy young woman with no history of significant medical problems. In intraoral examination there was a mandibular body fracture in socket place with mobile parts, the patient was unable to open her mouth (Figure 1,2). Based on details indication of extraction was carries and pain of first molar. The radiographic examination revealed a mandibular unfavorable body fracture including buccal and lingual table and also a remained root (Figure 3,4 and 5). The patient also stated that while the dentist was extracting the tooth, he had used the forceps without supporting the alveolar bone segment. After general anesthesia with nasal intubation, by intaoral vestibular incision the fracture line was exposed and the remained root was surgically extracted, then upper and lower IMF screws was placed and the patient fixed in occlusion with wire, then the fracture line was reduced anatomically and fixed with miniplates and screws, then IMF wires opened and mouth opening was controlled and incision sutured. The patient had IMF for 2 weeks (Figure 6,7), an uneventful recovery and normal occlusion.

\section{Discussion}

Dentists encounter a wide range of hard-tissue injuries in practice. Dental extractions are one of the most common procedures in dentistry and may lead to several complications, including sinus complications, osteitis, infection, dysesthesia, pain, and bleeding [1,2]. Frequently seen injuries include those associated with concomitant dentoalveolar trauma and those inadvertently caused by the dentist in practice. Factors affecting the incidence and etiology of iatrogenic mandibular fractures include the magnitude of tooth impaction, type of tooth angulation, length of roots, patient age, age and experience of the surgeon, presence of a cyst or tumor around teeth, systemic disease or medications that may impair bone strength, preoperative infections in the site, and inadequate preoperative examination [35]. A fracture occurs when the strength of the bone is overcome by the forces acting on it. The mandible is fractured 2-3 times more frequently than other facial bones because it has less bony support $[6,7]$. The body of the mandible is naturally strengthened by a system of buttresses extending onto the ramus. We believe that the fracture
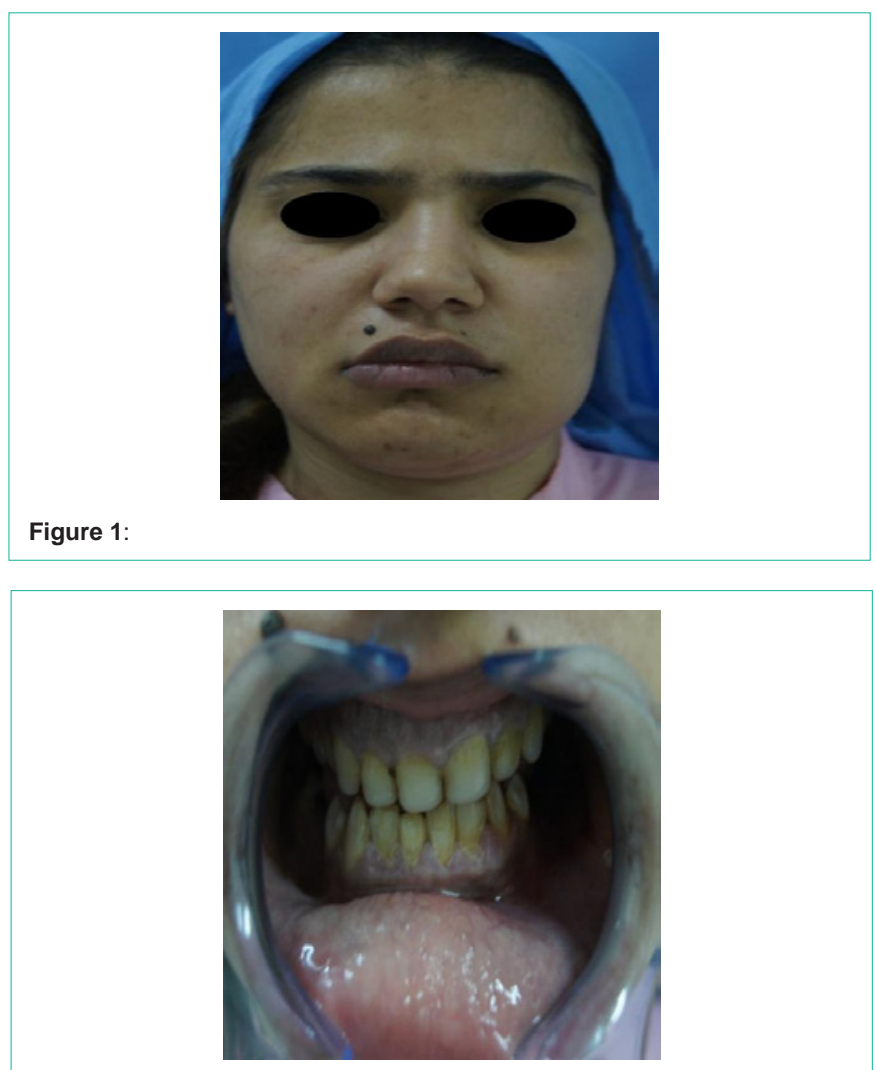

Figure 2:

described occurred primarily due to wrong technique. Open or closed reduction methods may be used for the management of mandibular fractures. In closed reduction procedures, dental wiring or bars are applied to the dental arch to achieve satisfactory occlusion. Closed reduction is indicated in non-displaced favorable fractures. The open reduction of mandibular fractures is reserved for displaced unfavorable fractures, multiple fractures, cases in which IMF is contraindicated or impossible, and cases in which IMF is avoided to increase patient comfort. The terms "favorable" and "unfavorable" are used to describe mandibular fractures [8]. There was no similar study but in case of mandibular fracture due to impacted wisdom
Austin J Dent - Volume 4 Issue 5 - 2017

ISSN : 2381-9189 | www.austinpublishing group.com

Mehrabizadeh et al. (C) All rights are reserved
Citation: Faryabi J and Mehrabizadeh H. Unfavorable Mandibular Body Fracture Associated with First Molar Removal: Report of a New Case. Austin J Dent. 2017; 4(5): 1081. 


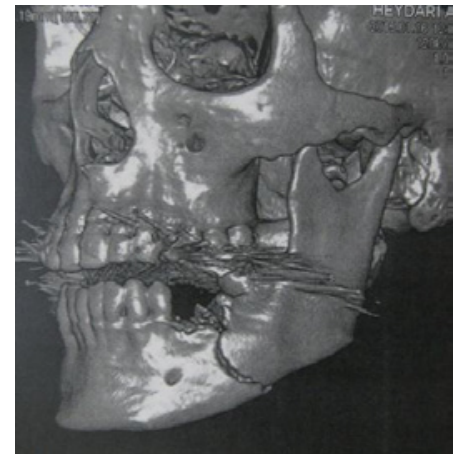

Figure 3:

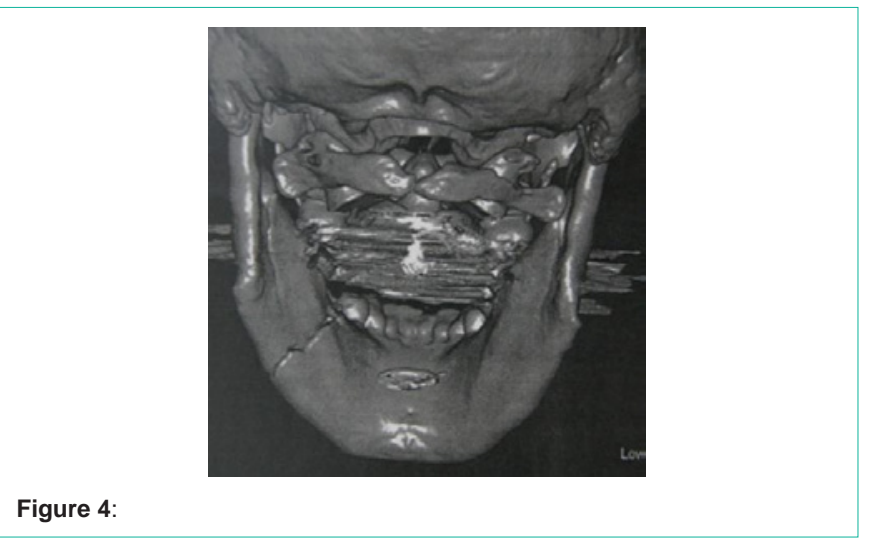

Figure 4:

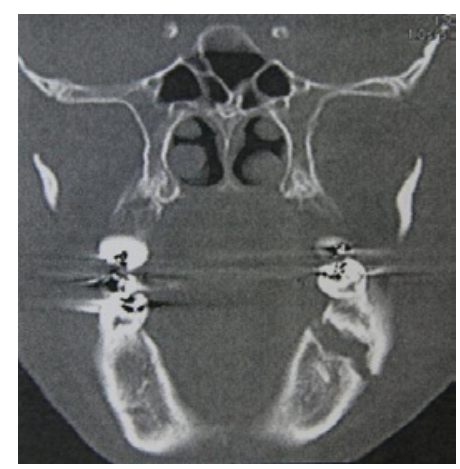

Figure 5:

teeth, patients were at least 26 years of age [9]. Our female patient was 28 years old were at low risk for mandibular fracture. Wagner [10] noted that more $(70 \%)$ iatrogenic mandibular fractures occur on the left side, perhaps due to the reduced visualization of an operation site on this side provided by the surgeon's normal position. Bodner, et al. [9] found no difference in the occurrence of fractures on the right and left sides. However, we believe that the higher incidence of fractures on the left side reflects the dentist's position, from which excessive and uncontrolled force may readily be applied to the left side of a patient's mandible by a right-handed surgeon. The fracture described was probably caused by the application of excessive force to the mandible. Because our patient was young-aged, ankylosis was not a factor in our case. Osteoporotic women have a high risk of iatrogenic fracture due to the low resistance of the bone to standard biting forces

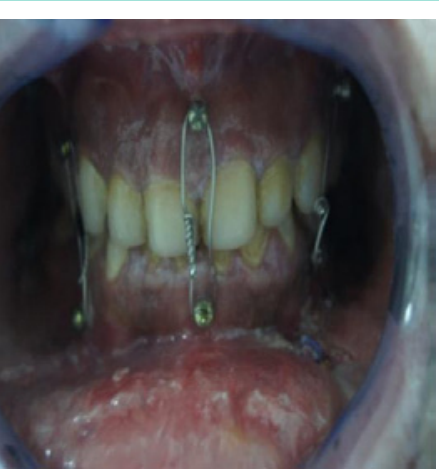

Figure 6:

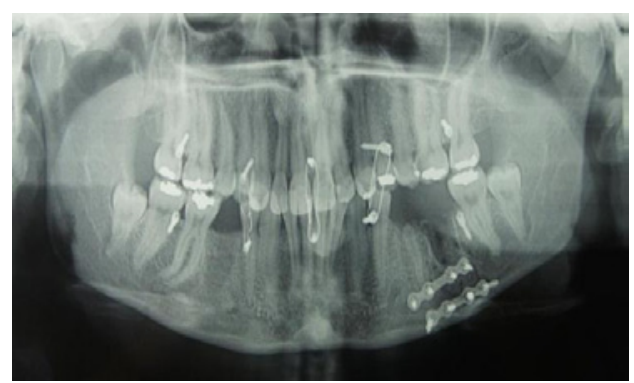

Figure 7:

[10] but our patient has no problem.

\section{Conclusion}

Clinicians must inform the patient of the potential risks of treatment before making treatment. Not only forceps extraction of a resistant third molar but also first molar may result in fracture of mandible. According to our knowledge, in the literature no mandibular fracture case was reported to be associated with the upper first molar extraction. It is suggested that during the forceps extraction of the molar teeth, supporting alveolar bone segment must be performed. Once these complications may occur unavoidably as a result of routine dental procedure under local anesthesia, the patient should refer to a specialist. To use simple fixation techniques, start appropriate medication decrease the complications and the patient's complaints, accelerate the healing process.

\section{References}

1. Bodner K, Brennan PA, McLeod NM. Characteristics of iatrogenic mandibular fractures associated with tooth removal: review and analysis of 189 cases. $\mathrm{Br}$ J Oral Maxillofac Surg. 2010; 49: 567-572.

2. Niedzielska I, Kowol I, Sroczynska-Grula A. Iatrogenic injury during extraction of lower molar teeth. Dent Med Probl. 2009; 46: 501-505.

3. Sakr K, Farag IA, Zeitoun IM. Review of 509 mandibular fractures treated at the University Hospital, Alexandria, Egypt. Br J Oral Maxillofac Surg. 2009; 44: 107-111.

4. Tanaka N, Tomitsuka K, Shionoya K, Andou H, Kimijima Y, Tashiro T, et al. Aetiology of maxillofacial fracture. Br J Oral Maxillofac Surg. 1994; 32: 19-23.

5. Thorn JJ, Møgeltoft M, Hansen PK. Incidence and aetiological pattern of jaw fractures in Greenland. Int J Oral Maxillofac Surg. 1986; 15: 372-379.

6. Subhashraj K, Ramkumar S, Ravindran C. Pattern of mandibular fractures in Chennai, India. Br J Oral Maxillofac Surg. 2008; 46: 126-127. 
7. Haug RH, Prather J, Indresano AT. An epidemiologic survey of facial fractures and concomitant injuries. J Oral Maxillofac Surg. 1990; 48: 926-932.

8. Neelima AM. Textbook of oral maxillofacial surgery, 2nd ed. New Delhi, India Jaypee Brothers; 2008.

9. Contar CM, de Oliveira P, Kanegusuku K, Berticelli RD, Azevedo-Alanis LR,
Machado MA. Complications in third molar removal: a retrospective study of 588 patients. Med Oral Patol Oral Cir Bucal. 2010; 15: e74-78.

10. Wagner KW, Otten JE, Schoen R, Schmelzeisen R. Pathological mandibular fractures following third molar removal. Int J Oral Maxillofacial Surg. 2005; 34: $722-726$.
Austin J Dent - Volume 4 Issue 5 - 2017

ISSN : 2381-9189 | www.austinpublishing group.com

Mehrabizadeh et al. (C) All rights are reserved
Citation: Faryabi J and Mehrabizadeh H. Unfavorable Mandibular Body Fracture Associated with First Molar Removal: Report of a New Case. Austin J Dent. 2017; 4(5): 1081. 